\title{
A rare case of superficial median artery of high brachial origin: anatomical and clinical considerations of the superficial brachiomedian artery
}

\author{
Lazar Jelev, Georgi P. Georgiev \\ Department of Anatomy, Histology and Embryology, Medical University Sofia, Sofia, Bulgaria
}

\begin{abstract}
A rare case of median artery with unusually high origin and superficial course, also termed superficial brachiomedian artery, was observed during routine anatomical dissection of the right upper extremity of a 63-year-old Caucasian female cadaver. The aberrant artery arose from the initial part of the brachial artery. In the arm region it followed a superficial course and at the elbow passed beneath the bicipital aponeurosis. In the upper third of the forearm, the variant artery passed under the muscular belly of the palmaris longus and flexor digitorum superficialis muscle. Accompanying the median nerve, the unusual median artery passed through the carpal tunnel and participated in the formation of the superficial palmar arch. Due to its variant course and location, the superficial brachiomedian artery may cause compression on the nerve within the carpal tunnel or nerve ischemia may result from an accidental arterial injury.
\end{abstract}

Key words: human; superficial brachiomedian artery; variation

Anatomy 2011;5:39-43, (c) 2011 TSACA

\section{Introduction}

In the early embryonic life an arterial vessel appears running through the long axis of the anterior forearm that accompanies and supplies with blood large part of the median nerve. In adults, this artery can be nearly always found as a small vessel close to the median nerve and usually ending before it reaches the wrist. In such cases the artery is called "a. comitans nervi mediani" or according to others this is a "median artery of antebrachial type" (76-100\% of the individuals). ${ }^{[1-4]}$ Sometimes, when a vessel of significant size is present accompanying the median nerve and reaching the hand to participate in the fingers' blood supply, this is called "median artery of palmar type" (1.5-12\% of the individuals). ${ }^{[1-4]}$ Dissection studies ${ }^{[5-10]}$ reveal that commonly the median artery arises from the arteries in the elbow region and is located deep below the superficial flexor group of the anterior antebrachial region in close proximity to the median nerve. In some instances either the median artery course or origin or both may have significant variations. ${ }^{[1,12]}$

Such a rare case of variant median artery is described here that could present some diagnostic and therapeutic challenges in the field of hand surgery.

\section{Case Report}

An intriguing case of unusual origin and course of the median artery was observed during routine anatomical dissection of the right upper extremity of a 63 -year-old Caucasian female cadaver (Figures 1 and 2). A small variant superficial artery was found starting from the initial part of the brachial artery. In the arm region (Figure 1), this artery, accompanied by a pair of small veins, was located below the brachial fascia on the antero-medial 
side of the median nerve. At the elbow region, the superficial artery passed beneath the bicipital aponeurosis anterior to the medial epicondyle of the humerus. In the upper third of the forearm, the variant artery coursed between the palmaris longus and flexor carpi radialis just before gaining the lateral border and deep surface of the flexor digitorum superficialis and descended accompanying the median nerve. In the lower third of the forearm, the aberrant artery once again appeared superficially within the median nerve sheath and coursing through the carpal tunnel it entered the palmar region. After completing the dissection in that region it was revealed that the variant artery participated in the formation of the superficial palmar arch (Figure 2). Along the course through the extremity, the diameter of the artery diminished from $2.1 \mathrm{~mm}$ at the origin to $1.3 \mathrm{~mm}$ in the palmar region. Because of the origin, course and termination pattern, the so described artery was considered to be a "superficial" median artery of high brachial origin or a "superficial" brachiomedian artery according to the terms proposed by Rodríguez-Niedenführ et al..$^{[2]}$
In the anterior cubital region, the brachial artery divided as usual into the ulnar and radial arteries. The latter, however, had a superficial antebrachial course and descended in the furrow between the brachioradialis and flexor carpi ulnaris muscles covered by the antebrachial fascia. In the hand region, there was a complete superficial palmar arch composed of the ulnar artery, small superficial branch of the radial artery and the additional superficial median artery.

\section{Discussion}

The origin and course of the median artery in the forearm region have been largely investigated and thus wellknown. ${ }^{[1-4,13-15]}$ The anterior interosseous, common interosseous, ulnar arteries or the caudal angle between the ulnar and common interosseus arteries have been described as common origins of the median artery. ${ }^{[2,16]}$ Rarely, the median artery can arise from the radial artery. ${ }^{[2]}$ All of the authors have described the same course of the median artery in the forearm - between the anterior surface of the median nerve and the deep surface

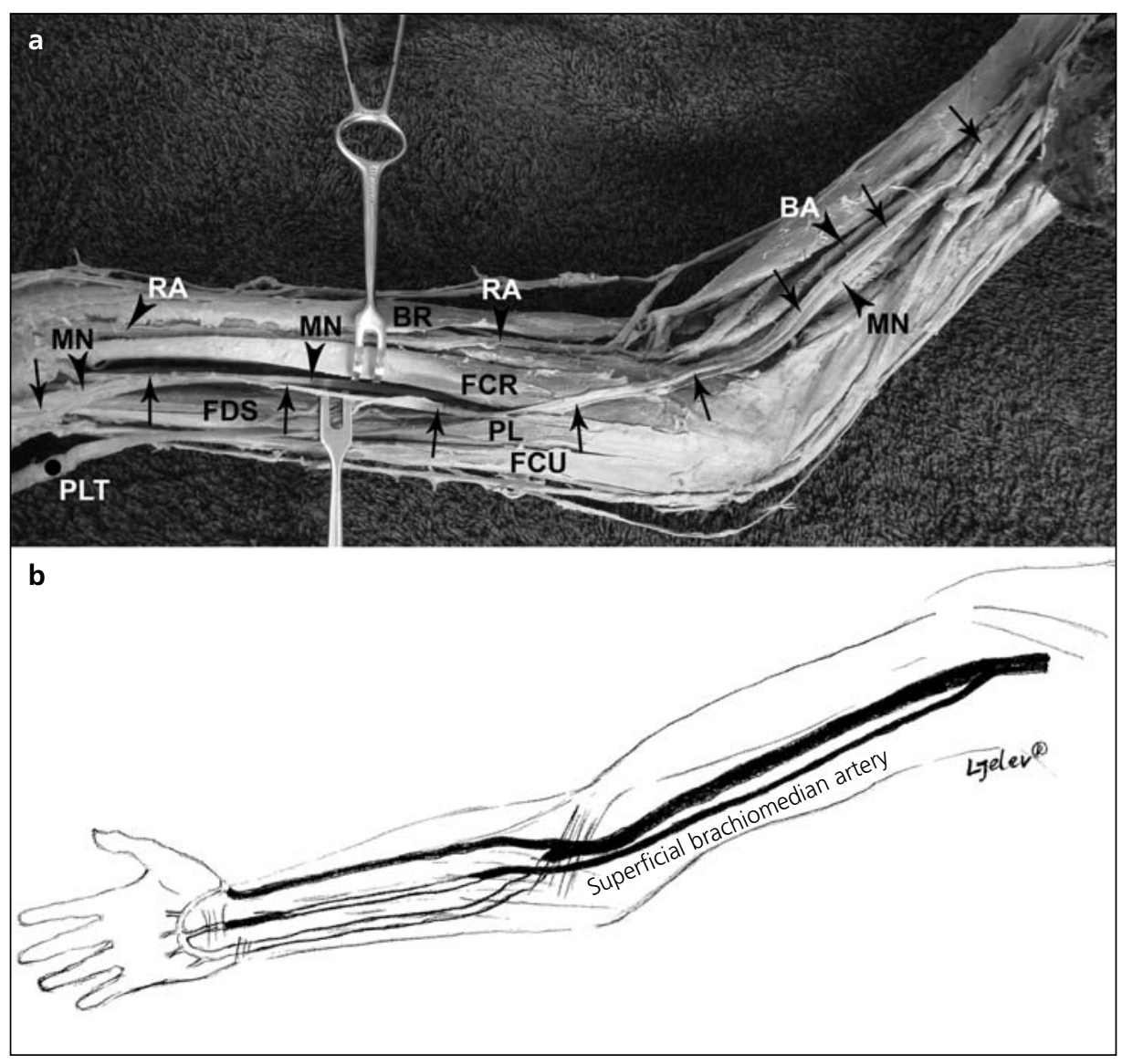

Figure 1. Photograph (a) and scheme (b) of the dissected right upper extremity, showing the entire course of the superficial median artery (arrows). BA: brachial artery; RA: radial artery; MN: median nerve; BR: brachioradialis muscle; FCR: flexor carpi radialis muscle; FDS: flexor digitorum superficialis muscle; PL: palmaris longus muscle; PLT: palmaris longus tendon; FCU: flexor carpi ulnaris muscle. 
Figure 2. Photograph of the dissected right hand, showing the palmar course of the superficial median artery (arrows). The flexor retinaculum was cut and the content of the carpal tunnel shown. RA: radial artery; SPBr: superficial palmar branch of the radial artery; UA: ulnar artery; SPA: superficial palmar arch; MN: median nerve; FCR: flexor carpi radialis muscle; FDS: flexor digitorum superficialis muscle; PLT: palmaris longus tendon; PA: palmar aponeurosis.

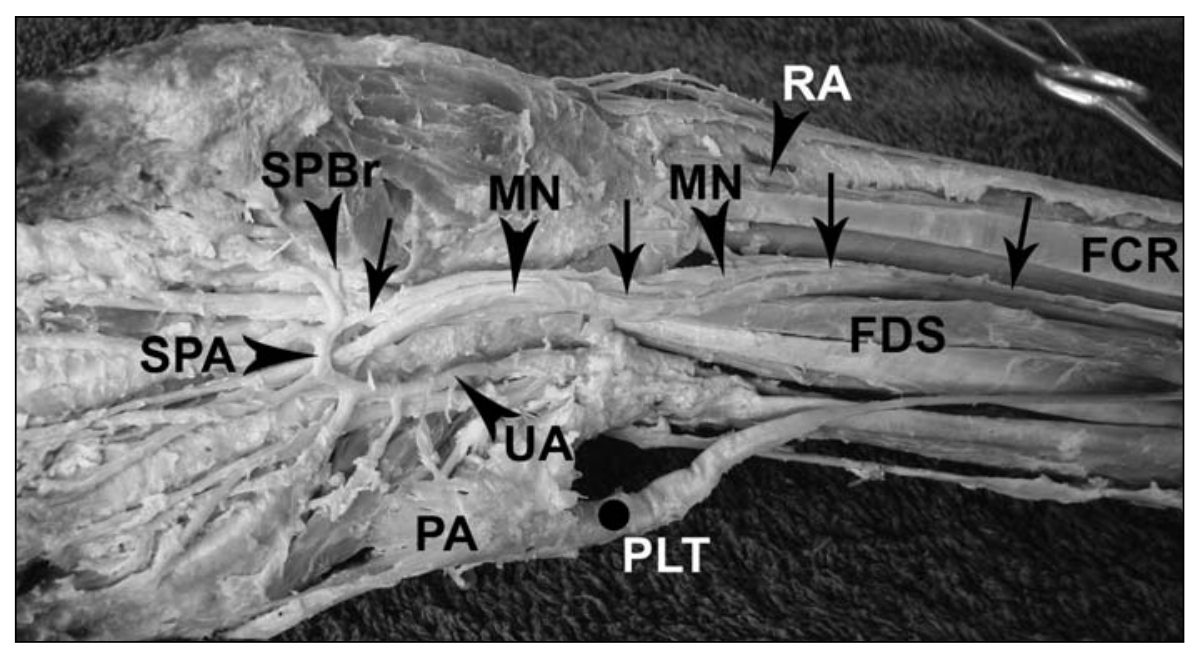

of the flexor digitorum superficialis. ${ }^{2}$ In some rare cases $(1 \%)^{[14,17]}$ a median artery originating at the elbow may course anterior to the antebrachial flexor muscles ${ }^{[13,14,1,1,18]}$ and then it is called "superficial" median artery. The rarest variation concerning the median artery, however, is a combination of superficial course and origin above the elbow. Such an artery, found in approximately $0.5 \%$ of the cases, ${ }^{2}$ arising from the axillary or brachial arteries and having superficial course through the extremity is termed "superficial" median artery of high origin or "superficial" brachiomedian artery. ${ }^{[2,13,17,19]}$ It could be regarded as the rarest type of superficial below-theelbow continuations of a superficial brachial artery along with the superficial brachioulnar $(0.7-7 \%)$, superficial brachioradial $(0.13-0.67 \%)$ and superficial brachioulnoradial arteries $(0.14-1.3 \%){ }^{[2]}$

The embryological origin and development of the median artery is not completely understood and deserves further studies. ${ }^{[10]}$ According to numerous authors, the median artery is a transitory vessel that represents the arterial axis of the forearm during early embryonic life. It normally regresses in the second embryonic month. ${ }^{[20,21]}$ Based on the differences in incidence of the median artery between the neonates and adults, Kopuz et al. ${ }^{[10]}$ have raised the possibility that the median artery can regress at a much later stage, possibly during the perinatal period and early infancy. Persisting median artery in adults has been considered as retention of a primitive arterial pattern. ${ }^{[20-22]}$ Rodríguez-Niedenführ et al. ${ }^{[1]}$ proposed that the palmar pattern of the median artery is a remnant of the embryonic model whiles the antebrachial pattern represents its partial regression. Recently, the prenatal formation of the upper limb arteries, including the median artery, was rather described as a gradual tran- sition between the capillary network and definite vessels, than progression and regression of some parts of a preliminary common arterial model. ${ }^{[23]}$

Several clinical disorders can result from the presence of a strongly developed median artery and its variable relation to the median nerve. ${ }^{[3]}$ In the upper forearm region a variant course of the median artery through the median nerve or some of its branches could be a cause of "pronator teres syndrome" ${ }^{,[2]}$ and "anterior interosseus nerve syndrome" ${ }^{[25]}$ In the carpal tunnel, a median artery of palmar type, especially with an external diameter more than $2.0 \mathrm{~mm},{ }^{[26]}$ can increase the pressure on the median nerve and thus to be blamed as a cause of carpal tunnel syndrome ${ }^{[3,4,27]}$ described in a number of surgical case reports. ${ }^{[28-31]}$ Sometimes, median artery injuries such as thrombosis, ${ }^{[25,32-35]}$ aneurysm, ${ }^{[36]}$ calcification ${ }^{[37]}$ and traumatic rupture ${ }^{[38]}$ have been identified as causes of carpal tunnel syndrome. In all of these cases, the excision of the median artery within the carpal canal is curative, but first, the presence of sufficient anastomotic blood supply of the hand should be confirmed by ultrasonographic, color Doppler ultrasonographic and magnetic resonance imaging modalities. ${ }^{[3,40]}$ According to Natsis et al. ${ }^{[4]}$ the median artery may also cause damage to the median nerve by ischaemia. The pathogenesis of the latter is observed especially when the anastomotic branches between the median and the radial and ulnar arteries, as well as the superficial palmar arch are poor.

The variant artery described here accompanies the median nerve in the carpal tunnel and may cause compression effect on it. The superficial location of the artery may impose some other challenges. A superficial wound along the brachial and elbow course of the aber- 
rant artery may cause sudden decrease of the blood supply of the median nerve, resulting in motor and sensory losses in the nerve distribution area. Accidental injection into the superficial brachiomedian artery, instead of a vein, is possible or the artery can be ligated instead of the vein when radial artery flap is prepared. ${ }^{[17]}$

\section{References}

1. Rodríguez-Niedenführ M, Sañudo JR, Vázquez T, Nearn L, Logan B, Parkin I. Median artery revisited. J Anat 1999;195:57-63.

2. Rodríguez-Niedenführ M, Vázquez T, Nearn L, Ferreira B, Parkin I, Sañudo JR. Variations of the arterial pattern in the upper limb revisited: a morphological and statistical study, with a review of the literature. J Anat 2001;199:547-66.

3. Claassen H, Schmitt O, Wree A. Large patent median arteries and their relation to the superficial palmar arch with respect to history, size consideration and clinic consequences. Surg Radiol Anat 2008;30:57-63.

4. Natsis K, Iordache G, Gigis I, et al. Persistent median artery in the carpal tunnel: anatomy, embryology, clinical significance, and review of the literature. Folia Morphol (Warsz) 2009;68:193-200.

5. McCormack LJ, Cauldwell EW, Anson BJ. Brachial and antebrachial arterial patterns; a study of 750 extremities. Surg Gynecol Obstet 1953;96:43-54.

6. Coleman SS, Anson BJ. Arterial patterns in the hand based upon a study of 650 specimens. Surg Gynecol Obstet 1961;113:409-24.

7. Henneberg M, George BJ. High incidence of the median artery of the forearm in a sample of recent southern African cadavers. J Anat 1992;180:185-8.

8. Henneberg M, George BJ. A further study of the high incidence of the median artery of the forearm in Southern Africa. J Anat 1992;181:151-4.

9. Kopuz C, Gülman B, Barış S. Persistent median artery: an anatomical study in neonatal and adult cadavers. Kaibogaku Zasshi 1995;70:577-80.

10. Kopuz C, Barış S, Gülman B. A further morphological study of the persistent median artery in neonatal cadavers. Surg Radiol Anat 1997;19:403-6.

11. Srivastava SK, Pande BS. Anomalous pattern of median artery in the forearm of Indians. Acta Anat (Basel) 1990;138:193-4.

12. Wood SJ, Abrahams PH, Sañudo JR, Ferreira BJ. Bilateral superficial radial artery at the wrist associated with a radial origin of a unilateral median artery. J Anat 1996;189:691-3.

13. Adachi B. Anatomie der Japaner I. Das Arteriensystem der Japaner, Bd I: A. pulmonalis, Aorta bis Arcus volaris profundus. Kioto: Verl. der Keiserlich-Japan Univ.; 1928.p.364-72.

14. Lippert H, Pabst R. Arterial Variations in Man. München: J.F. Bergmann Verlag; 1985.p.72-3.

15. Nayak SR, Krishnamurthy A, Kumar SM, et al. Palmar type of median artery as a source of superficial palmar arch: a cadaveric study with its clinical significance. Hand (NY) 2010;5:31-6.
16. Tsuruo $Y$, Ueyama $T$, Ito $T$, et al. Persistent median artery in the hand: a report with a brief review of the literature. Anat Sci Int 2006;81:242-52.

17. Nakatani T, Izumi A, Tanaka S. Bilateral superficial median arteries. J Anat 1999;194:475-7.

18. Gruber W. Ueber die Arteria mediana antibrachii superficialis, Arteria ulnaris antibrachii superficialis und Duplicität der Arteria ulnaris. Archiv für Anatomie und Physiologie und wissenschaftliche Medicin 1867;668-87.

19. Quain R. Anatomy of the Arteries of the Human Body. London: Taylor \& Walton; 1844.p.235-71.

20. De Vriese B. Recherches sur l'évolution des vaisseaux sanguins des membres chez l' homme. Arch Biol 1902;18:665-730.

21. Müller E. Beiträge zur Morphologie des Gefässystems. I. Die Armarterien des Menschen. Anat Hefte 1903;22:377-575.

22. Singer E. Embryological pattern persisting in the arteries of the arm. Anat Rec 1933;55:403-9.

23. Rodríguez-Niedenführ M, Burton GJ, Deu J, Sañudo JR. Development of the arterial pattern in the upper limb of staged human embryos: normal development and anatomic variations. J Anat 2001;199:407-17.

24. Jones NF, Ming NL. Persistent median artery as a cause of pronator syndrome. J Hand Surg Am 1988;13:728-32.

25. Proudman TW, Menz PJ. An anomaly of the median artery associated with the anterior interosseous nerve syndrome. J Hand Surg Br 1992;17:507-9.

26. Barfred T, Højlund AP, Bertheussen K. Median artery in carpal tunnel syndrome. J Hand Surg Am 1985;10:864-7.

27. Bilgin SS, Olcay SE, Derincek A, Adıyaman S, Demirtaş AM. Can simple release relieve symptoms of carpal tunnel syndrome caused by a persistent median artery? Clinical experience. Arch Orthop Trauma Surg 2004;124:154-6.

28. Galassi E, Benfenati A, Tognetti F, Pozzati E. Persistence of the median artery: possible cause of the carpal tunnel syndrome. Riv Neurol 1980;50:159-66.

29. Lavey EB, Pearl RM. Patent median artery as a cause of carpal tunnel syndrome. Ann Plast Surg 1981;7:236-8.

30. Boles DM, Tobias PV, Spiro F. Carpal tunnel syndrome due to compression by an anomalous median artery. Surg Neurol 1982;17:99-100.

31. Rayan GM. Persistent median artery and compression neuropathy. Orthop Rev 1986;15:241-4.

32. Burnham PJ. Acute carpal tunnel syndrome. Median artery thrombosis as cause. Arch Surg 1963;87:645-6.

33. Levy M, Pauker M. Carpal tunnel syndrome due to thrombosed persisting median artery. A case report. Hand 1978;10:65-8.

34. Fumière E, Dugardeyn C, Roquet ME, Delcour C. US demonstration of a thrombosed persistent median artery in carpal tunnel syndrome. JBR-BTR 2002;85:1-3.

35. Kele H, Verheggen R, Reimers CD. Carpal tunnel syndrome caused by thrombosis of the median artery: the importance of high-resolution ultrasonography for diagnosis. Case report. J Neurosurg 2002;97:471-3. 
36. Toranto IR. Aneurysm of the median artery causing recurrent carpal tunnel syndrome and anatomic review. Plast Reconstr Surg 1989;84:510-2.

37. Dickinson JC, Kleinert JM. Acute carpal-tunnel syndrome caused by a calcified median artery. A case report. J Bone Joint Surg Am 1991;73:610-1.

38. Faithfull DK, Wallace RF. Traumatic rupture of median artery an unusual cause for acute median nerve compression. J Hand Surg Br 1987;12:233-5.
39. Gassner EM, Schocke M, Peer S, Schwabegger A, Jaschke W, Bodner G. Persistent median artery in the carpal tunnel: color Doppler ultrasonographic findings. J Ultrasound Med 2002;21:455-61.

40. Pierre-Jerome C, Smitson RD Jr, Shah RK, Moncayo V, Abdelnoor M, Terk MR. MRI of the median nerve and median artery in the carpal tunnel: prevalence of their anatomical variations and clinical significance. Surg Radiol Anat 2010;32:315-22.

Correspondence to: Lazar Jelev, MD, PhD

Department of Anatomy, Histology and Embryology Medical University of Sofia

Blvd. Sv. Georgi Sofiisky 1

BG-1431 Sofia, Bulgaria

Phone: +359 29172636; Fax: +359 28518783

e-mail: ljelev@abv.bg

Conflict of interest statement: No conflicts declared. 